OPEN ACCESS

Edited by:

Marina Rufino Salinas Fortes,

The University of

Queensland, Australia

Reviewed by:

Deqiang Miao,

Washington State University,

United States

Jose Antonio Tapia

University of Extremadura, Spain

${ }^{*}$ Correspondence:

Dawit Tesfaye

dawit.tesfaye@colostate.edu

Specialty section: This article was submitted to Animal Reproduction -

Theriogenology,

a section of the journal

Frontiers in Veterinary Science

Received: 02 September 2020

Accepted: 26 October 2020

Published: 19 November 2020

Citation:

Gebremedhn S, Ali A, Gad A

Prochazka $R$ and Tesfaye $D$ (2020) Extracellular Vesicles as Mediators of Environmental and Metabolic Stress

Coping Mechanisms During Mammalian Follicular Development.

Front. Vet. Sci. 7:602043

doi: 10.3389/fvets.2020.602043

\section{Extracellular Vesicles as Mediators of Environmental and Metabolic Stress Coping Mechanisms During Mammalian Follicular Development}

\author{
Samuel Gebremedhn ${ }^{1,2}$, Asghar Ali ${ }^{1}$, Ahmed Gad ${ }^{3,4}$, Radek Prochazka ${ }^{3}$ and \\ Dawit Tesfaye ${ }^{1,2 *}$ \\ ${ }^{1}$ Animal Reproduction and Biotechnology Laboratory, Department of Biomedical Sciences, Colorado State University, \\ Fort Collins, CO, United States, ${ }^{2}$ Department of Animal, Rangeland and Wildlife Sciences, Mekelle University, Mekelle, \\ Ethiopia, ${ }^{3}$ Institute of Animal Physiology and Genetics of the Czech Academy of Sciences, Liběchov, Czechia, ${ }^{4}$ Department \\ of Animal Production, Faculty of Agriculture, Cairo University, Giza, Egypt
}

Extracellular vesicles are evolutionarily conserved nano-sized phospholipid membraned structures and released from virtually all types of cells into the extracellular space. Their ability to carry various molecular cargos (mRNA, miRNA, proteins, and lipids) from one cell to the other to exert functional impact on the target cells enables them to play a significant role in cell to cell communication during follicular development. As the molecular signals carried by extracellular vesicles reflect the physiological status of the cells of origin, they are expected to mediate any effect of environmental or metabolic stress on the follicualr cells and the growing oocyte. Recent studies have evidenced that reproductive cells exposed to various environmental stressors (heat and oxidative stress) released extracellular vesicles enriched with mRNA and miRNA associated with stress response mechanisms. Moreover, the metabolic status of post-calving cows could be well-reflected in the follicular extracellular vesicle's miRNA profile, which signified the potential role of extracellular cellular vesicle molecular signals in mediating the effect of metabolic stress on follicular and oocyte development. In the present review, the potential role of extracellular vesicles in mediating the effect of environmental and metabolic stress in various reproductive cells and oocytes are thoroughly discussed Moreover, considering the importance of extracellular vesicles in shuttling protective or rescuing molecular signals during stress, their potential usage as means of targeted delivery of molecules to mitigate the effect of stress on oocytes are addressed as the focus of future research.

Keywords: extracellular vesicles, environmental stress, follicular development, metabolic stress, intrafollicular cells

\section{INTRODUCTION}

Throughout their lifespan, including embryonic development, growth, maturity, and aging, animals are exposed to various environmental (heat, cold, oxidative, chemicals, and others) and endogenous stressors. Recurrent environmental and metabolic stress pose significant risk and disruption of the reproductive physiology. Over the past five decades, the intensive selection practices of dairy cows for higher milk yield have resulted in tremendous success in increasing the 
net milk yield. However, the increase in milk production has resulted in a concomitant reduction in fertility traits (1), which increases the likelihood of culling cows with lower fertility, causing a reduction in the total amount of milk produced and farm profitability (2). This is attributed to the negative correlation of production traits and vulnerability to environmental and metabolic stress. Environmental and metabolic stress factors induce changes in the steroidogenic capacity of follicles, mainly reduce estradiol production in the dominant follicles, which impairs ovulation associated processes $(3,4)$. Oocytes obtained from follicles exposed to both environmental and metabolic stressors have lower developmental competence (5), accompanied by reduced ability to fertilize and develop to the blastocyst stage and establish a pregnancy (6). Exposure to both environmental and metabolic stress impair the communication between the oocyte and the surrounding follicular fluid. The bi-directional communication between follicular cells and the oocyte is mainly carried out either directly through gap junction or secretion of paracrine and autocrine molecules (7). The recent advancements in the discovery and characterization of extracellular vesicles (EVs) released from various cell types have provided an additional layer into the existing and wellknown mechanism of cell-to-cell communication (8). It has been reported that EVs are important in shuttling bioactive molecules (mRNAs, miRNAs, and proteins), which could reflect the physiological status of the originating cells $(9,10)$. The bioactive molecular content of EVs released from cells subjected to a variety of environmental and metabolic stressors are distinct and divergent compared to the EVs obtained from the unstressed cells counterparts (11). For instance, cells subjected to heat stress released heat shock proteins via EVs (12), and upon uptake by recipient cells, it resulted in the modulation of the immunological responses of the recipient cells (13). Similarly, supplementation of cells with EVs obtained from cells challenged with oxidative stress transported protective messages to the recipient cells upon subsequent exposure to oxidative stress (14). Recently, we have reported the rescuing effect of EVs from $\mathrm{H}_{2} \mathrm{O}_{2}$ treated bovine granulosa cells by modulating the NRF2 signaling pathways (15). Experimental models involving the application of heat, oxidative, and metabolic stress factors on cultured granulosa could provide insights into the possible association of intrafollicular communications with the oocyte. Identifying the conserved and stressor-specific bioactive molecules shuttled via EVs would be beneficial in addressing the specific stress-associated decline in oocyte maturation. The present review highlights the role of EVs in modulating metabolic and environmental stresses. The importance of EVs in intrafollicular communication and ovarian physiology, the rescuing and protective impact of EVs against subsequent stressors are thoroughly discussed.

\section{INTRAFOLLICULAR COMMUNICATION BETWEEN THE FOLLICULAR CELLS AND THE OOCYTE}

During the course of folliculogenesis, continuous bi-directional communication between the oocyte and its encircling cumulus cells, granulosa cells, and theca cells, to exchange an oocyte and somatic cell factors, is indispensable for the ovulation of a developmentally competent oocyte, that can undergo through fertilization and the processes of embryogenesis (16). The gap junction is the main mechanism of the cross-talk between the oocyte and the follicular cells, which involves the formation of the protein family connexins known for their variability in the permeability, which in turn aids in the transportation of molecules of lower molecular weight lower than $1 \mathrm{KDa}$ in size, which are ions, metabolites, and amino acids between the oocyte and the follicular somatic cells (17). The follicular microenvironment has two physical barriers that separate the oocyte from the follicular cells, the follicular fluid-filled antrum and the zona pellucida (ZP). Nevertheless, the constant flow of information between the oocyte and the follicular cells is maintained through the transzonal projection (TZP), irrespective of the physical barriers (18). The cumulus cells, which are located adjacent to the oocyte are the primary origin of the TZP. In addition to the cumulus cells, which are proximate to the oocyte, cumulus cells positioned at distant layers from the oocyte also are reported to stretch a few TZPs (19). The number of TZP in the growing oocyte is significantly higher, which signifies a growing quest for somatic cells factors for its maturation and the oocyte factors for the specialization of the surrounding somatic cells (20), and signifies the stimulatory effect of the oocyte on the surrounding somatic cells to generate more TZP. The study further showed that the oocyte-secreted GDF9 stimulates the surrounding cells to generate more TZP through the SMAD signaling pathway. In a separate study, oocyte from mouse model deficient in GDF9 showed to have a malformation of TZP (21). It has been evidenced that, at the tip of the TZP a split is formed and EVs have been detected at the tip of the splits, which signifies the importance of TZP in shuttling EVs between the somatic cells and the oocyte (22).

The formation of an antrum cavity filled with a serumlike fluid exudate called the follicular fluid is the defining phenomenon of the later stages of mammalian follicular development (23). The follicular fluid, which is a mixture of proteins, lipids, and nucleotide and ions, secreted from the surrounding somatic cells and the oocyte, and blood plasma, which cross the follicular barrier through the capillaries of the theca cells, serves as an enclosed microenvironment for the maturing oocyte (24). The follicular fluid is a source of gonadotropins, growth factors, enzymes, and proteins and the biochemical composition of the follicular fluid could also be a reflector of the pathophysiological conditions of the corresponding follicle and predictors of the oocyte quality (25). The follicular fluid in the antrum segregates the oocyte from the mural granulosa cells and theca cells, which creates a conducive microenvironment for normal development of the oocyte, and further facilitate the exchange of cellular messages between them (24). The physical separation between the oocyte and the follicular cells leads to the formation of two distinct subpopulations of granulosa cells. The outer layers of granulosa cells will be separated from the granulosa cells layers adjacent and surrounding the oocyte, which becomes cumulus cells. Nevertheless, the communication between the 
oocyte and follicular cells is still maintained mainly through paracrine signaling. Here, each subpopulation of granulosa cells is being exposed to the FSH and oocyte secreting factors, at differential gradients (26). For instance, the interaction of the oocyte secreted factors like the GDF9 and BMP15 with the FSH and growth factors like the IGF1 is crucial in promoting the proliferation and differentiation of the granulosa cells and the cumulus cells, respectively (27).

\section{EXTRACELLULAR VESICLES AS MEANS OF INTRAFOLLICULAR COMMUNICATIONS}

Extracellular vesicles (EVs) are evolutionarily conserved nanosized, phospholipid bilayer membraned structures of varying sizes released from virtually all types of cells through the exocytosis process into the extracellular space (8). EVs are reported to be present throughout an organism's biological fluids providing pleiotropic functions (28). Due to their heterogeneity in the size, shape, membrane protein, and the originating cells (29), EVs can broadly be categorized as microvesicles, exosomes, and apoptotic bodies. Microvesicles are generated by the outward budding of the plasma membranes with irregular shapes and a size range of 100-1,000 $\mathrm{nm}$. Exosomes are the smallest fraction of EVs, with a diameter ranging from 30 to $150 \mathrm{~nm}$ and formed from the intraluminal vesicles (ILV), with the multivesicular bodies (MVB) and released to the extracellular space upon fusion with the plasma membrane (30). The largest fractions of EVs are the apoptotic bodies, with a diameter range of 1 to $5 \mu \mathrm{m}$, which arise from the highly regulated cellular disintegration during apoptosis (31). EVs are also differentiated based on the molecular bioactive molecular content they encapsulated. Exosomes and MVs encapsulate an array of cytoplasmic contents including RNAs, proteins, and lipids (32), while apoptotic bodies are equipped with nuclear components and cellular organelles (33). The presence of specific membrane-associated proteins including the tetraspanins, the CD63, CD81, and CD9, and other proteins including ALIX and TSG101 is the hallmark of EVs (34). Studies have suggested that the encapsulated bioactive molecules within EVs can exert phenotypic changes and modulate the expression of genes in the secreting and nearly and distantly located recipient cells (35). Cells actively select the amount of EVs and the type of bioactive molecules to shuttle depending on the cellular physiological and environmental conditions, like stress and diseases (36). Upon reaching the target cells, EVs can interact with their target cells either through EVs membrane protein interaction and the cellular receptors or through the dissolution of the EVs protein by the enormous protease activity in the extracellular space making the EVs release their content and act on the receptors of the target cells. Besides, the membrane of the EVs could be fused with the membrane of the recipient cells to release the content of the EVs and incorporate it into the cellular content (37).

EVs are abundantly present in virtually all reproductive biological fluids including follicular fluid (38), oviductal fluid (39, 40), uterine fluid (41), amniotic fluid (42), and spent cell culture media (15) and embryos culture media (43). EVs carry molecular conservatories including mRNA, miRNAs, and proteins, which indicate the physiological status of the originating cells $(9,10)$. EVs are reported to be present in the follicular fluid of bovine (38, 44,45 ), equine (46), human (47) and are essential in the transport of RNAs, miRNAs, and protein to recipient cells during follicular development. In bovine, the uptake of follicular EVs is reported to be associated with the alteration transcript abundance in the recipient oocytes (48), and granulosa cells (38), and enhanced the cumulus expansion during in vitro oocyte maturation (44), the rate of development of in vitro fertilized oocytes to the blastocyst stage (49) and proliferation of granulosa cells (50). It is not only the amount of EVs in the biological fluid that varies depending on the physiological status of the reproductive organ, but also the molecular cargo carried by these EVs. For instance, a small growing follicle not only contains a higher concentration of EVs in the follicular fluid, but also a large set of EV-coupled miRNAs, which evidenced the molecular dynamics during the processes of oocyte growth. Intriguingly, EVs isolated from follicular fluid of small follicles have better potential to support oocyte maturation cumulus expansion with inter-species wide conserved manner (44).

One of the key factors that contribute to the expansion of the cumulus cells by promoting the response to FSH is an oocyte secreted factor named the cumulus expansion enabling factor (CEEF) (51). The CEEF has been speculated to be a combination of oocyte secreted and several other proteins, including the oocyte-secreted GDF9 (52) and the TGFBB1 (53), which have been studied due to their positive impact on cumulus expansion. In support of this notion, denaturation of oocyte maturation conditioned media at higher temperature or treatment with proteinase $\mathrm{K}$ completely inhibited the impact of CEEF in inducing the cumulus expansion (54). This signifies the fact that oocyte secreted proteins can be released as components of the CEEF into the extracellular space. The experiment further examined the size of the protein in the conditioned maturation media by using a $100-\mathrm{kDa}$ filter membrane and it was shown that the flow-through component of the conditioned media did not enhance the expansion of the cumulus cells. This implies that the CEEF could be a protein molecule with higher molecular weight (>100 kDa) (54). However, in another study, it was shown that the $25 \mathrm{kDa}$ TGBB1 protein partially plays the role of CEEF (55), signifying the fact that the CEEF is not a single protein, rather a complex of protein molecules. In addition, the presence and activity of CEEF in follicular fluid was investigated by supplementing follicular fluid obtained from small and large follicles during in vitro oocyte maturation (54). In that study, it was shown that the cumulus cells expanded extensively in the presence of follicular fluid from the smaller follicles, contrary to the cumulus cells cultured with follicular fluid obtained from larger follicles. Similarly, maturation media conditioned with mural granulosa cells of smaller follicles resulted in elevated CEEF activity and the expansion of the cumulus cells as opposed to the granulosa cells from the larger follicles. This can be attributed to the higher number of FSH receptors in small follicle granulosa cells as compared to the large ones. 
To date, the role of EVs in shuttling the CEEF between the oocyte and the surrounding somatic cells is not reported. However, reports on the differential effect of EVs supplementation from the small and large follicles on cumulus expansion could indicate the potential role of EVs in shuttling the CEEFs between the ovarian somatic cells and gamete and vise versa (44). Nevertheless, further study is needed to profile the proteome content of the EVs derived from the follicular fluid at different stages of the follicular development, which could lead to the identification of either known or novel CEEFs circulating in the follicular environment.

Due to its enclosed microenvironment, the follicle is convenient to study the EV-signaling mechanism, as the source of the EVs and recipient cells can easily be pinpointed. Another advantage of the follicular microenvironment is the remarkable stability of the RNA molecules in the follicular fluid and other reproductive biological fluid, irrespective of the higher nuclease activity, which could be attributed to the encapsulation in EVs (9). This makes the EVs encapsulated RNAs promising molecular tools in the search for the diagnostic markers of various reproductive pathophysiological conditions. For instance, analysis of the EV-mediated miRNAs derived from human follicular fluid and the corresponding serum samples revealed specific miRNAs enriched in the EVs of the follicular fluid with an important role in ovarian functions (47). The study showed the miRNAs specifically enriched in the EVs of follicular fluid including miR-99a, miR-100, miR-132, and miR-218 are involved in the maturation process of the follicles, while the miR132, miR-212, and miR-214 negatively regulate genes known to encode inhibitors of follicular maturation (47). Supplementation of oocytes with EVs from follicular fluid has been shown to alter the transcript abundance of the recipient oocyte and played enhancing the competence role of the oocyte to reach the blastocyst stage (49). In an attempt to determine the impact of follicular fluid EVs on the physiology and morphology of the cumulus-oocyte complexes (COCs) and the associated changes in the gene expression, follicular fluid EVs derived from small and large bovine antral follicles were supplemented to COCs (44). The study further showed that the EVs from the follicular fluid of smaller follicles harbor more bioactive molecules and pose a tremendous positive impact on the expansion of the COCs and enrichment of the COCs expansion marker genes, Ptgs2, Ptx3, and Tnfaip6 in both bovine and mouse. Interestingly, the study verified that supplementation of bovine follicular fluid EVs into mouse COCs induced the expansion of cumulus cells (44). This signifies the fact that the evolutionary conservation of the EVs functions and opens a room for inter-species alternatives for the remedies in reproductive pathophysiological conditions. EVs of the follicular fluid carry miRNAs reported to be involved in key pathways related to oocyte maturation, such as the WNT, TGFß, MAPK, and ErbB signaling pathways $(46,47)$. It is also worth noting the developmental competence of bovine oocytes is closely associated with the EV-coupled miRNA profile of the corresponding follicular fluid. (38). The study further revealed the higher number of miRNAs being released via EVs from follicular fluid, which surrounds the immature oocytes compared to the EVs derived from follicular fluid encompassing mature oocyte. This is in agreement with the previous finding, which highlighted that the smaller follicles release more EVs into the follicular fluid compared to the larger antral follicles (56). The study further affirms that the miRNAs content of EVs from the follicular fluid is reported to show variation according to the stage of development. For instance, the expression of miR-204, miR-92b, miR-328a-3p, miR-424e-3p, and miR-450a is reported to progressively increase, while the expression of miR-19a-3p and miR-335 showed a progressive decline in response to the increase in the size and growth of follicles. Follicles of variable size have been reported to have distinct sets of miRNAs (56), which could have a differential impact on the proliferation of granulosa cells (50). Similarly, in mare, the follicular fluid EVs obtained from the preovulatory and the mid-estrous stage follicles are enriched with miR-372, miR-27b, and miR-382 and these miRNAs have an inhibitory role on genes like the Inhibitor of DNA Binding/Differentiation 2 (ID2), which are downregulated in the granulosa cells of mare preovulatory dominant follicles (57). A summary of the EV-mediated transfer of bioactive molecules in reproductive biofluids is indicated in Table 1.

\section{IMPACT OF ENVIRONMENTAL AND METABOLIC STRESS ON FOLLICULAR DEVELOPMENT AND THE INVOLVEMENT OF EVS IN MEDIATING THE STRESS COPING MECHANISMS}

Among the determinant factors that contribute to the decline of female fertility is exposure to both environmental and metabolic stresses. Among the environmental stressors, oxidative (15) and heat stress (71) is reported to impair follicular development and function of the follicular cells. Moreover, metabolic stressors, which enhance the accumulation of non-esterified fatty acids in the circulation are also reported to impair the steroidogenic function of the follicular cells (72).

\section{Oxidative Stress}

Among the stress-inducing factors that arise from environmental and physiological insults is oxidative stress, which is a phenomenon, where the amount of cellular ROS production overwhelms the intrinsic production of scavenging antioxidants $(73,74)$. The ROS are the most abundant forms of intermediates generated during the oxygen consumption process (75) and are involved in oxidative stress (76). Even though a moderate level of ROS is beneficial for normal progression of cellular functions (77), excessive production can surpass the natural antioxidant system and this creates an unfitting environment for female reproduction (78). During ovarian follicular development, there is a complex relationship between the production of ROS and the counterbalancing antioxidants in a stage-dependent manner (79). For instance, during the preovulatory stage, the postLH inflammatory precursors generate excessive ROS, which is important to induce ovulation (80). Among the free radicals that lead to the excessive accumulation of intracellular ROS and subsequent cellular damage, the $\mathrm{H}_{2} \mathrm{O}_{2}$ has a longer cellular halflife and can enter into the nucleus (81). Thus, it is a widely used 
TABLE 1 | Summary of EV-mediated release of bioactive molecules and the associated biological functions.

\begin{tabular}{|c|c|c|c|c|}
\hline $\begin{array}{l}\text { Reproductive } \\
\text { biofluid/media }\end{array}$ & $\begin{array}{l}\text { Bioactive molecules released } \\
\text { in EVs }\end{array}$ & EV-associated biological functions & Species & References \\
\hline Follicular fluid & $\begin{array}{l}\text { miRNAs }^{1,2,4,5,6,13} \text {, transcripts } \\
\text { associated with cumulus } \\
\text { expansion }{ }^{3}, \text { C-type natriuretic } \\
\text { peptide (CNP) and natriuretic } \\
\text { peptide receptors subtype } 2 \\
\text { (NPR2) }^{7} \text {, transcriptome } \\
\text { proteome }^{8,9,10}\end{array}$ & 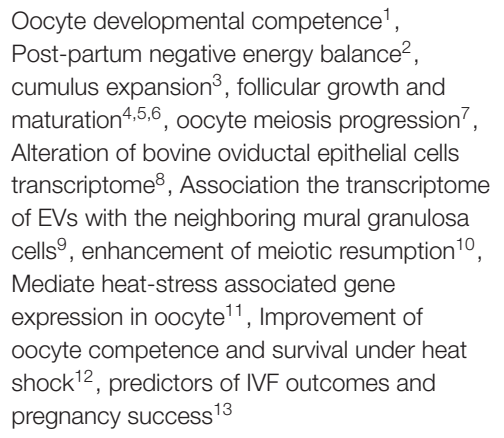 & $\begin{array}{l}\text { Bovine }{ }^{1,2,3,5,7,8,10,12} \\
\text { Equine }^{4}, \text { Human }^{6,13} \\
\text { Porcine }^{9}, \text { Feline }^{10}\end{array}$ & $\begin{array}{l}{ }^{1}(38),{ }^{2}(45),{ }^{3}(44),{ }^{4}(46), \\
{ }^{5}(56),{ }^{6}(47),{ }^{7}(58),{ }^{8}(59), \\
9(60),{ }^{10}(61),{ }^{11}(48), \\
{ }^{12}(62),{ }^{13}(63)\end{array}$ \\
\hline Oviductal fluid & Proteins ${ }^{1,2,3,4}$, miRNAs $^{2,4}$ & $\begin{array}{l}\text { Embryo-oviduct cross-talk }{ }^{1} \text {, gamete-oviduct } \\
\text { interations }{ }^{2} \text {, Change in the Phospholipid } \\
\text { Composition of in vitro developed Bovine } \\
\text { Embryos }^{3} \text {, Hormonal impact of the estrous } \\
\text { cycle on EVs secretion }^{4} \text {, regulation of sperm } \\
\text { motility and survival }^{5} \text {, regulation of polyspermy } \\
\text { during porcine in vitro fertilisation }{ }^{6} \text {, } \\
\text { improvement of birth rates after embryo } \\
\text { transfer }^{7}\end{array}$ & Bovine $^{1,2,3,}$ Porcine ${ }^{4,5,6}$ Mouse $^{7}$ & $\begin{array}{l}{ }^{1}(39),{ }^{2}(64),{ }^{3}(65),{ }^{4}(66), \\
{ }^{5}(67),{ }^{6}(68),{ }^{7}(69)\end{array}$ \\
\hline $\begin{array}{l}\text { Granulosa } \\
\text { cells spent } \\
\text { culture media }\end{array}$ & $\begin{array}{l}\text { miRNAs }{ }^{1} \text {, heat-stress associated } \\
\text { transcripts (HSP70, HSP90, } \\
\text { GRP78, and GRP94) }{ }^{1} \text { and } \\
\text { oxidative Stress-associated } \\
\text { transcripts (NRF2, PRDX1, CAT, } \\
\text { and TXN1) }\end{array}$ & $\begin{array}{l}\text { The protective impact of EV-associated } \\
\text { miRNAs against heat stress }{ }^{1} \text {, rescuing role of } \\
\text { EVs against oxidative stress }{ }^{2}\end{array}$ & Bovine $e^{1,2}$ & ${ }^{1}(70),{ }^{2}(15)$ \\
\hline
\end{tabular}

Superscript numbers correspond to the references listed in the last column of the table.

free radical for the induction of oxidative stress under in vitro experiments in various cell types. Reports showed that $\mathrm{H}_{2} \mathrm{O}_{2}$ induces granulosa cell apoptosis by regulating the ROS-JNKp53 pathway (82). Bovine granulosa cells treated with $\mathrm{H}_{2} \mathrm{O}_{2}$ accumulated a significantly higher amount of ROS accompanied by reduced activity of mitochondria and elevated expression of the stress-related transcription factor NRF2 and its downstream antioxidant transcripts (CAT, PRDX1, and TXN1) (15). One of the factors responsible for the impaired cellular functions of in vitro developed oocyte is the generation of oxidative stress from the suboptimal maturation condition, which could contribute to the lower success of in vitro embryo production (83). The extent that oocyte is affected by oxidative stress during in vitro maturation process depends on the intrinsic antioxidant properties and how fast this is replenished during the maturation process (84). Interestingly, oocytes with intact cumulus cell mass are endowed with higher antioxidant activity compared to denuded ones (84).

The involvement of EV-mediated molecule transfer in response to oxidative stress has been previously reported. The EVs released from mouse mast cells transport protective RNA messages to the recipient cells upon coincubation against subsequent exposure to oxidative stress (14). In our previous experiment, we showed that EVs released from granulosa cells treated with $\mathrm{H}_{2} \mathrm{O}_{2}$ are enriched with NRF2 and antioxidant enzymes (CAT and TXN1), signifying the fact that EVs could partly reflect the cellular stress conditions considering the presence of stress-associated transcripts both in the cells and the released EVs (15). In the same study, the co-incubation of EVs obtained from $\mathrm{H}_{2} \mathrm{O}_{2}$ challenged granulosa cells rescued the recipient granulosa cells by reducing the accumulation of intracellular ROS. This signifies the fact that stress associated EVs contain molecular signals, which could play a protective or rescuing role against subsequent stress. Nevertheless, the abundance of the oxidative stress-associated transcripts like the NRF2 and its downstream antioxidants in the recipient cells was elevated and subsequently, reduce intracellular ROS accumulation (15). This could be because of the fact that pretreatment of cells with $\mathrm{H}_{2} \mathrm{O}_{2}$ before the supplementation of EVs has already activated the transcription of the NRF2 signaling pathway. In a separate study, EVs obtained from cells exposed to $\mathrm{H}_{2} \mathrm{O}_{2}$ were supplemented to recipient cells before subsequent $\mathrm{H}_{2} \mathrm{O}_{2}$ challenge showed to have a protective impact in the recipient cells against subsequent oxidative stress (14). This demonstrates the fact that the timing of stress primed EVs supplementation in relation to the timing of the subsequent $\mathrm{H}_{2} \mathrm{O}_{2}$ exposure determines the transcriptional activation pattern in the recipient cells.

\section{Heat Stress}

Environmental heat stress during summer seasons is a dominant stressor in the dairy and beef industry that leads to impairment 
in various reproductive processes including oocyte maturation, embryo development, gonadotropin secretion, ovarian follicular growth, steroidogenesis, development of corpus luteum, and uterine endometrial responses $(4,85)$. Summer heat damage has a long-lasting effect on dairy cows and a period of 2-3 estrous cycles are required to fully recover from heat stressinduced damages (4). Exposure of oocytes to high temperature during the maturation period resulted in impairment in the rearrangement of their microtubules and microfilaments, damaged spindle apparatus, an increased proportion of oocytes arrested at metaphase, the nuclear maturation (5) and resulted in a lower rate of fertilization (6). Similarly, oocytes collected during the summertime are reported to have lower mitochondrial distribution compared to oocytes collected during wintertime, which was accompanied by the induction of oxidative stress and apoptosis (86). Heat stress also impairs the function of granulosa cells, which in turn compromises ovarian function and the developmental competence of the accompanied oocytes (87). We demonstrated the deleterious effect of heat stress on granulosa cells using an in vitro cell culture model, in which exposure of cells to elevated temperature resulted in reduced cellular proliferation, increased apoptosis, increased ROS accumulation, and reduced mitochondrial activity (88). Granulosa cells respond to heat exposure by activating the heat shock proteins (HSP) family and the unfolded protein response (UPR) (89, 90). Among the heat shock protein family, the HSP70 is reported to be significantly elevated in granulosa cells exposed to heat stress (71).

The cellular reserve of the HSPs is also reported to be present in the extracellular space. For instance, cells subjected to heat stress are reported to release HSPs into the extracellular space via EVs $(12,91,92)$ and are involved in modulating the immunological responses of the recipient cells (13). Similarly, cells exposed to heat stress are reported to release the HSPs into the extracellular space via EVs, which could be a reflector of the cellular heat stress conditions (93). Cells exposed to heat stress are reported to release EVs that could pose a bystander effect on recipient neighboring cells. The bystander effect can be explained by the reduced rate of apoptosis and DNA damage in the untreated recipient cells (94). Interestingly, the study showed that the cells supplemented with EVs from heat-stressed cells became more resistant to subsequent heat stress compared to the untreated counterparts. We recently experimented on the EVs-mediated transfer of protective signals against heat stress in bovine granulosa cells (70). Data showed that granulosa cells subjected to heat stress $\left(42^{\circ} \mathrm{C}\right)$ released a significantly higher number of EVs to the culture media compared to the cells kept under normal temperature $\left(37^{\circ} \mathrm{C}\right)$. Moreover, the EVs of the heat-stressed granulosa cells were enriched with HSP70, HSP90, and SOD1 and tend to have more GRP78 and GRP94 compared to the EVs of untreated granulosa cells. Interestingly, the miRNA profile of the EVs showed that the heat-stressed EVs are enriched with miR-1246, which is also previously reported to be abundantly expressed in the circulation of heat-stressed Holstein Frisian cows (95). A recent study in bovine has evidenced that supplementation of both the whole follicular fluid and isolated EVs from follicular fluid reversed the damage of the heat stress on the oocyte and improved the cleavage and blastocyst rates (62). Interestingly, supplementation oocytes with only follicular EVs have a better impact than the whole follicular fluid in terms of improving cleavage and blastocyst rate. This signifies that the EVs play a major role in reversing the damage incurred by heat stress on the oocytes.

\section{Metabolic Stress}

The intensive selection for high milk yield in the past decades has resulted in a significant increment in the amount of milk per lactation per cow. However, a concomitant reduction in the fertility traits of high yielding dairy cows was also observed (1). The decline in fertility traits is associated with early lactation post-partum negative energy balance (NEB) (96). Follicles obtained from post-partum cows under NEB undergo several unfavorable metabolic changes that affect the developmental competence of oocytes $(97,98)$. Similarly, granulosa cells of cows under NEB exhibited lower expression of genes linked to Vitamin A and D metabolism, suggesting the detrimental effect of metabolic stress on bovine follicular development (99). Among the major metabolic changes in high-producing dairy cows is the elevation of free fatty acids (FFA) in the circulation, which are released from adipose tissues during the early postpartum period (100). Besides the changes in the composition of post-partum follicular fluid, cows under NEB are characterized by the elevated concentration of the non-esterified fatty acid (NEFA) and b-hydroxybutyrate concentrations (BHB) during the first 2-4 weeks post-partum and start to decline from the 6th week post-partum both in the follicular fluid and serum (101). The concentration of palmitic (C16:0), stearic acid (C18:0), and oleic acid (C18:1) are reported to be elevated in the serum of cows under NEB (102). Under in vitro culture conditions, supplementation of individual and pooled NEFA components (C16:0 and C18:0) to bovine granulosa cells at a dose as low as $150 \mathrm{mM}$ induced apoptosis and reduced proliferation of cells, which signifies the toxic effects of NEFA accumulation during the post-partum period on the follicular cells in bovine (72).

We recently examined the miRNAs content of EVs derived from follicular fluid of cows under divergent metabolic status post-calving and results showed a massive down-regulation of miRNAs in follicular fluid EVs of cows under NEB (45). Based on the miRNA fingerprints carried by follicular EVs, cows under positive energy balance post-partum closely resembled heifers than cows under NEB conditions. Moreover, the oocytes derived from these cows during early post-partum showed altered epigenetic profiles compared to those derived during the late post-partum period (103). Interestingly, the study identified around 33,000 differentially methylated regions (DMRs) were found to be specific to early-post-partum and these were located within genes involved in metabolic, carbon metabolism, and fatty acid metabolisms. However, the association of EV-coupled molecular signatures with an altered epigenome profile of oocytes needs further investigation. 


\section{DYNAMICS OF EV-MEDIATED miRNAs IN FOLLICULAR CELLS IN RESPONSE TO ENVIRONMENTAL STRESS}

One of the fundamental aspects of EVs-mediated transfer of bioactive molecules is the balance between the molecules remained in the cells and those released into the extracellular space. EVs released into the body fluid could indicate the level of intracellular hemostasis (104). Similarly, cells could also release EVs as a mechanism to remove toxicants from cells (105). For instance, EV-mediated release of b-catenin through EVs led to the reduced intracellular reserve of the $B$ catenin pool, which in turn downregulate the intracellular WNT signaling pathway (106). Nevertheless, it is arguable whether the intracellular reserve of certain bioactive molecules will be reduced irrespective of its enrichment in the corresponding EVs. In addition, the exposure of cells to either environmental or metabolic stress could potentially have a unique pattern of release of a selected bioactive molecule. To address this, we performed a comparison of the miRNAs profile in granulosa cells and the corresponding EVs in relation to exposure to heat stress (70). MiRNAs were sorted according to their expression pattern in the heat-stressed group, where miRNAs with positive or negative fold changes are considered as up or down-regulated miRNAs, respectively. Accordingly, four different scenarios of miRNAs expression in granulosa cells and EV-mediated release were observed namely, (A) miRNAs upregulated in both the cells and the corresponding EVs, (B) miRNAs upregulated in the granulosa cells, but downregulated in the corresponding EVs, (C) miRNAs downregulated in the granulosa cells, but upregulated in the corresponding EVs, and (D) miRNAs downregulated in both the granulosa cells and the corresponding EVs. The mechanisms of these patterns and the selective release or maintaining of these miRNAs could either be a reflector of the cellular homeostasis or as mechanisms to reduce the cellular reserve of selected miRNA, which are detrimental to the survival of cells during the exposure to environmental or metabolic stressors. Contrary to this, the miRNAs, which are preferentially enriched in the cells as opposed to the corresponding EVs or vice-versa could be beneficial to the cells to cope with the exogenous stress and contribute to the

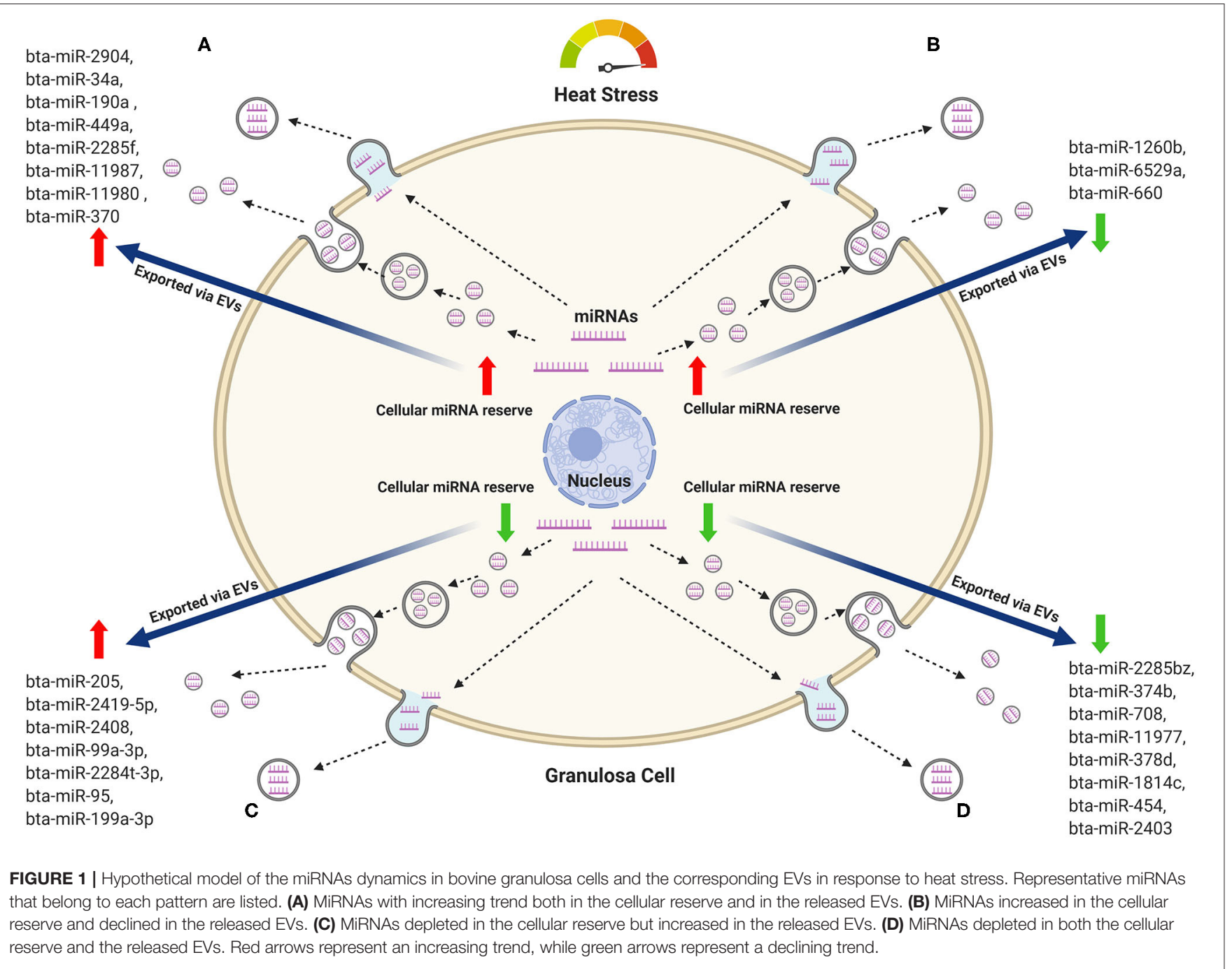


enhanced development of stress resistance. A hypothetical model that describes the dynamics of miRNA abundance in the cellular reserve and released EVs as a response to heat stress is indicated in Figure 1.

\section{THE FUTURE IMPLICATION OF EVs IN MAMMALIAN FEMALE FERTILITY DURING ENVIRONMENTAL AND METABOLIC STRESS}

The importance of EVs as molecular cargo in mediating mammalian follicular development has been characterized in several reproductive biofluids. Nevertheless, the functional role of these EVs and their cargo molecules are not fully understood. Considering the important roles of EVs in shuttling the protective and rescuing signals in follicular cells, it would highlight the potential usage of EVs as a means of molecule delivery, which could be utilized for future applications to mitigate the effect of stress on oocytes and embryo development. The molecular characterization of the cargo of EVs with a potential impact on oocyte and embryo development could lead to the discovery of molecular markers for the development of stress-associated infertility treatment strategies. Therefore, characterizing the content of EVs released from granulosa cells and oviductal epithelial cells after exposure to environmental and metabolic

\section{REFERENCES}

1. Lucy MC. Reproductive loss in high-producing dairy cattle: Where will it end? J Dairy Sci. (2001) 84:1277-93. doi: 10.3168/jds.S0022-0302(01)70158-0

2. Hansen PJ. Effects of heat stress on mammalian reproduction. Philos Trans $R$ Soc B Biol Sci. (2009) 364:3341-50. doi: 10.1098/rstb.2009.0131

3. Wolfenson D, Lew BJ, Thatcher WW, Graber Y, Meidan R. Seasonal and acute heat stress effects on steroid production by dominant follicles in cows. Anim Reprod Sci. (1997) 47:9-19. doi: 10.1016/S0378-4320(96)01638-7

4. Roth Z, Meidan R, Shaham-Albalancy A, Braw-Tal R, Wolfenson D. Delayed effect of heat stress on steroid production in mediumsized and preovulatory bovine follicles. Reproduction. (2001) 121:745-51. doi: 10.1530/rep.0.1210745

5. Nabenishi H, Ohta H, Nishimoto T, Morita T, Ashizawa K, Tsuzuki Y. The effects of cysteine addition during in vitro maturation on the developmental competence, ROS, GSH and apoptosis level of bovine oocytes exposed to heat stress. Zygote. (2012) 20:249-59. doi: 10.1017/S0967199411000220

6. Roth Z, Hansen PJ. Disruption of nuclear maturation and rearrangement of cytoskeletal elements in bovine oocytes exposed to heat shock during maturation. Reproduction. (2005) 129:235-44. doi: 10.1530/rep.1.00394

7. Bosco D, Haefliger JA, Meda P. Connexins: key mediators of endocrine function. Physiol Rev. (2011) 91:1393-445. doi: 10.1152/physrev.00027.2010

8. Yáñez-Mó M, Siljander PRM, Andreu Z, Bedina Zavec A, Borràs FE, Buzas EI, et al. Biological properties of extracellular vesicles and their physiological functions. J Extracellular Vesicles. (2015) 4:27066. doi: 10.3402/jev.v4.27066

9. Valadi H, Ekström K, Bossios A, Sjöstrand M, Lee JJ, Lötvall JO. Exosome-mediated transfer of mRNAs and microRNAs is a novel mechanism of genetic exchange between cells. Nat Cell Biol. (2007) 9:654-9. doi: $10.1038 /$ ncb1596

10. Silva M, Melo SA. Non-coding RNAs in exosomes: new players in cancer biology. Curr Genomics. (2015) 16:295-303. doi: 10.2174/1389202916666150707154719

11. Yentrapalli R, Merl-Pham J, Azimzadeh O, Mutschelknaus L, Peters C, Hauck SM, et al. Quantitative changes in the protein and miRNA cargo of stress could provide useful insight about the survival mechanisms of reproductive cells and possible usage of these EVs as supplementation into the oocyte maturation and embryo culture medium to enhance stress-coping mechanism during oocytes maturation and embryos development. This will be relevant to address the issue of the qualitative and quantitative decline in the outcome of the in vitro production of embryos, which arises from the various stress-inducing factors under in vitro environment including the oxygen tension and culture media constituents compared to their in vivo counterparts.

\section{AUTHOR CONTRIBUTIONS}

SG and DT: literature searches. SG: writing. AA: illustration. DT, AA, AG, and RP: editing. DT, AG, and RP: approving and submission. All authors contributed to the article and approved the submitted version.

\section{FUNDING}

This project was partially funded by the Ministry of Education, Youth and Sports of the Czech Republic, Operational Program Research, Development and Education, the project EXCELLENCE in molecular aspects of the early development of vertebrates Grant number: CZ.02.1.01/0.0/0.0/15_003/0000460. plasma exosome-like vesicles after exposure to ionizing radiation. Int J Radiat Biol. (2017) 93:569-80. doi: 10.1080/09553002.2017.1294772

12. Zhan R, Leng X, Liu X, Wang X, Gong J, Yan L, et al. Heat shock protein 70 is secreted from endothelial cells by a non-classical pathway involving exosomes. Biochem Biophys Res Commun. (2009) 387:229-33. doi: 10.1016/j.bbrc.2009.06.095

13. Gastpar R, Gehrmann M, Bausero MA, Asea A, Gross C, Schroeder JA, et al. Heat shock protein 70 surface-positive tumor exosomes stimulate migratory and cytolytic activity of natural killer cells. Cancer Res. (2005) 65:5238-47. doi: 10.1158/0008-5472.CAN-04-3804

14. Eldh $M$, Ekström $K$, Valadi $H$, Sjöstrand $M$, Olsson $B$, Jernås $M$, et al. Exosomes communicate protective messages during oxidative stress; possible role of exosomal shuttle RNA. PLoS ONE. (2010) 5:e15353. doi: 10.1371/journal.pone.0015353

15. Saeed-Zidane M, Linden L, Salilew-Wondim D, Held E, Neuhoff C, Tholen E, et al. Cellular and exosome mediated molecular defense mechanism in bovine granulosa cells exposed to oxidative stress. PLOS ONE. (2017) 12:e0187569. doi: 10.1371/journal.pone.0187569

16. Matzuk MM, Burns $\mathrm{KH}$, Viveiros MM, Eppig JJ. Intercellular communication in the mammalian ovary: oocytes carry the conversation. Science. (2002) 296:2178-80. doi: 10.1126/science.10 71965

17. Zuccotti M, Merico V, Cecconi S, Redi CA, Garagna S. What does it take to make a developmentally competent mammalian egg? Hum Reprod Update. (2011) 17:525-40. doi: 10.1093/humupd/dmr009

18. Andrade GM, Del Collado M, Meirelles FV, da Silveira JC, Perecin F. Intrafollicular barriers and cellular interactions during ovarian follicle development. Anim Reprod. (2019) 16:485-96. doi: 10.21451/1984-3143-AR2019-0051

19. Jaffe LA, Egbert JR. Regulation of mammalian oocyte meiosis by intercellular communication within the ovarian follicle. Annu Rev Physiol. (2017) 79:23760. doi: 10.1146/annurev-physiol-022516-034102

20. El-Hayek S, Yang Q, Abbassi L, FitzHarris G, Clarke HJ. Mammalian oocytes locally remodel follicular architecture to provide the foundation 
for germline-soma communication. Curr Biol. (2018) 28:1124-31.e3. doi: 10.1016/j.cub.2018.02.039

21. Carabatsos MJ, Elvin J, Matzuk MM, Albertini DF. Characterization of oocyte and follicle development in growth differentiation factor9-deficient mice. Dev Biol. (1998) 204:373-84. doi: 10.1006/dbio.199 8.9087

22. Macaulay AD, Gilbert I, Caballero J, Barreto R, Fournier E, Tossou P, et al. The gametic synapse: RNA transfer to the bovine oocyte. Biol Reprod. (2014) 91:90. doi: 10.1095/biolreprod.114.119867

23. Hennet ML, Combelles CMH. The antral follicle: a microenvironment for oocyte differentiation. Int J Dev Biol. (2012) 56:819-31. doi: $10.1387 / \mathrm{ijdb} .120133 \mathrm{cc}$

24. Rodgers RJ, Irving-Rodgers HF. Formation of the ovarian follicular antrum and follicular fluid. Biol Reprod. (2010) 82:1021-9. doi: 10.1095/biolreprod.109.082941

25. Revelli A, Delle Piane L, Casano S, Molinari E, Massobrio M, Rinaudo P. Follicular fluid content and oocyte quality: from single biochemical markers to metabolomics. Reprod Biol Endocrinol. (2009) 7:40. doi: $10.1186 / 1477-7827-7-40$

26. Wigglesworth K, Lee KB, Emori C, Sugiura K, Eppig JJ. Transcriptomic diversification of developing cumulus and mural granulosa cells in mouse ovarian follicles. Biol Reprod. (2015) 92:23. doi: 10.1095/biolreprod.114.121756

27. Gilchrist RB, Ritter LJ, Armstrong DT. Oocyte-somatic cell interactions during follicle development in mammals. Anim Reprod Sci. (2004) 82-3:43146. doi: 10.1016/j.anireprosci.2004.05.017

28. Colombo M, Raposo G, Théry C. Biogenesis, secretion, and intercellular interactions of exosomes and other extracellular vesicles. Annu Rev Cell Dev Biol. (2014) 30:255-89. doi: 10.1146/annurev-cellbio-101512-122326

29. Taylor DD, Gercel-Taylor C. The origin, function, and diagnostic potential of RNA within extracellular vesicles present in human biological fluids. Front Genet. (2013) 4:142. doi: 10.3389/fgene.2013.00142

30. Théry C, Ostrowski M, Segura E. Membrane vesicles as conveyors of immune responses. Nat Rev Immunol. (2009) 9:581-93. doi: 10.1038/nri2567

31. Caruso S, Poon IKH. Apoptotic cell-derived extracellular vesicles: more than just debris. Front Immunol. (2018) 9:1486. doi: 10.3389/fimmu.2018.01486

32. Lee Y, El Andaloussi S, Wood MJA. Exosomes and microvesicles: extracellular vesicles for genetic information transfer and gene therapy. Hum Mol Genet. (2012) 21:R125-34. doi: 10.1093/hmg/dds317

33. Poon IKH, Lucas CD, Rossi AG, Ravichandran KS. Apoptotic cell clearance: basic biology and therapeutic potential. Nat Rev Immunol. (2014) 14:166-80. doi: $10.1038 /$ nri3607

34. Kumar D, Gupta D, Shankar S, Srivastava RK. Biomolecular characterization of exosomes released from cancer stem cells: Possible implications for biomarker and treatment of cancer. Oncotarget. (2015) 6:3280-91. doi: 10.18632 /oncotarget.2462

35. Vlassov AV, Magdaleno S, Setterquist R, Conrad R. Exosomes: current knowledge of their composition, biological functions, and diagnostic and therapeutic potentials. Biochim Biophys Acta. (2012) 1820:940-8. doi: 10.1016/j.bbagen.2012.03.017

36. van Niel G, D'Angelo G, Raposo G. Shedding light on the cell biology of extracellular vesicles. Nat Rev Mol Cell Biol. (2018) 19:213-28. doi: $10.1038 / \mathrm{nrm} .2017 .125$

37. Mathivanan S, Ji H, Simpson RJ. Exosomes: extracellular organelles important in intercellular communication. J Proteomics. (2010) 73:1907-20. doi: 10.1016/j.jprot.2010.06.006

38. Sohel MMH, Hoelker M, Noferesti SS, Salilew-Wondim D, Tholen E, Looft C, et al. Exosomal and non-exosomal transport of extra-cellular microRNAs in follicular fluid: implications for bovine oocyte developmental competence. PLoS ONE. (2013) 8:e78505. doi: 10.1371/journal.pone.0078505

39. Almiñana C, Corbin E, Tsikis G, Alcântara-Neto AS, Labas V, Reynaud $\mathrm{K}$, et al. Oviduct extracellular vesicles protein content and their role during oviduct-embryo cross-talk. Reproduction. (2017) 154:153-68. doi: 10.1530/REP-17-0054

40. Lopera-Vasquez R, Hamdi M, Maillo V, Gutierrez-Adan A, Bermejo-Alvarez P, Ramírez MÁ, et al. Effect of bovine oviductal extracellular vesicles on embryo development and quality in vitro. Reproduction. (2017) 153:461-70. doi: 10.1530/REP-16-0384
41. Qiao F, Ge H, Ma X, Zhang Y, Zuo Z, Wang M, et al. Bovine uterusderived exosomes improve developmental competence of somatic cell nuclear transfer embryos. Theriogenology. (2018) 114:199-205. doi: 10.1016/j.theriogenology.2018.03.027

42. Keller S, Rupp C, Stoeck A, Runz S, Fogel M, Lugert S, et al. CD24 is a marker of exosomes secreted into urine and amniotic fluid. Kidney Int. (2007) 72:1095-102. doi: 10.1038/sj.ki.5002486

43. Pavani KC, Hendrix A, van den Broeck W, Couck L, Szymanska K, Lin $\mathrm{X}$, et al. Isolation and characterization of functionally active extracellular vesicles from culture medium conditioned by bovine embryos in vitro. Int J Mol Sci. (2018) 20:38. doi: 10.3390/ijms20010038

44. Hung WT, Hong X, Christenson LK, McGinnis LK. Extracellular vesicles from bovine follicular fluid support cumulus expansion. Biol Reprod. (2015) 93:117. doi: 10.1095/biolreprod.115.132977

45. Hailay T, Hoelker M, Poirier M, Gebremedhn S, Rings F, Saeed-Zidane $\mathrm{M}$, et al. Extracellular vesicle-coupled miRNA profiles in follicular fluid of cows with divergent post-calving metabolic status. Sci Rep. (2019) 9:12851. doi: 10.1038/s41598-019-49029-9

46. da Silveira JC, Veeramachaneni DNR, Winger QA, Carnevale EM, Bouma GJ. Cell-secreted vesicles in equine ovarian follicular fluid contain miRNAs and proteins: a possible new form of cell communication within the ovarian follicle. Biol Reprod. (2012) 86:71. doi: 10.1095/biolreprod.111.093252

47. Santonocito M, Vento M, Guglielmino MR, Battaglia R, Wahlgren J, Ragusa $\mathrm{M}$, et al. Molecular characterization of exosomes and their microRNA cargo in human follicular fluid: bioinformatic analysis reveals that exosomal microRNAs control pathways involved in follicular maturation. Fertil Steril. (2014) 102:1751-61.el. doi: 10.1016/j.fertnstert.2014.08.005

48. Morales Dalanezi F, Mogollon Garcia HD, de Andrade Ferrazza R, Fagali Franchi F, Kubo Fontes P, de Souza Castilho AC, et al. Extracellular vesicles of follicular fluid from heat-stressed cows modify the gene expression of in vitro-matured oocytes. Anim Reprod Sci. (2019) 205:94-104. doi: 10.1016/j.anireprosci.2019.04.008

49. da Silveira JC, Andrade GM, Del Collado M, Sampaio RV, Sangalli JR, Silva LA, et al. Supplementation with small-extracellular vesicles from ovarian follicular fluid during in vitro production modulates bovine embryo development. PLoS ONE. (2017) 12:e0179451. doi: 10.1371/journal.pone.0179451

50. Hung W-T, Navakanitworakul R, Khan T, Zhang P, Davis JS, McGinnis $\mathrm{LK}$, et al. Stage-specific follicular extracellular vesicle uptake and regulation of bovine granulosa cell proliferation. Biol Reprod. (2017) 97:644-55. doi: 10.1093/biolre/iox106

51. Eppig JJ. Oocyte control of ovarian follicular development and function in mammals. Reproduction. (2001) 122:829-38. doi: 10.1530/rep.0.1220829

52. Elvin JA, Clark AT, Wang P, Wolfman NM, Matzuk MM. Paracrine actions of growth differentiation factor-9 in the mammalian ovary. Mol Endocrinol. (1999) 13:1035-48. doi: 10.1210/mend.13.6.0310

53. Salustri A, Ulisse S, Yanagishita M, Hascall VC. Hyaluronic acid synthesis by mural granulosa cells and cumulus cells in vitro is selectively stimulated by a factor produced by oocytes and by transforming growth factor-beta. J Biol Chem. (1990) 265:19517-23.

54. Procházka R, Nagyová E, Brem G, Schellander K, Motlík J. Secretion of cumulus expansion-enabling factor (CEEF) in porcine follicles. Mol Reprod Dev. (1998) 49:141-9. doi: 10.1002/(SICI)1098-2795(199802)49:2<141::AIDMRD5 $>3.0 . \mathrm{CO} ; 2-\mathrm{P}$

55. Tirone E, D’Alessandris C, Hascall VC, Siracusa G, Salustri A. Hyaluronan synthesis by mouse cumulus cells is regulated by interactions between follicle-stimulating hormone (or epidermal growth factor) and a soluble oocyte factor (or transforming growth factor beta1). J Biol Chem. (1997) 272:4787-94. doi: 10.1074/jbc.272.8.4787

56. Navakanitworakul R, Hung W-T, Gunewardena S, Davis JS, Chotigeat W, Christenson LK. Characterization and small RNA content of extracellular vesicles in follicular fluid of developing bovine antral follicles. Sci Rep. (2016) 6:25486. doi: 10.1038/srep25486

57. da Silveira JC, Carnevale EM, Winger QA, Bouma GJ. Regulation of ACVR1 and ID2 by cell-secreted exosomes during follicle maturation in the mare. Reprod Biol Endocrinol. (2014) 12:44. doi: 10.1186/1477-7827-12-44

58. Pioltine EM, Machado MF, da Silveira JC, Fontes PK, Botigelli RC, Quaglio AEV, et al. Can extracellular vesicles from bovine ovarian 
follicular fluid modulate the in-vitro oocyte meiosis progression similarly to the CNP-NPR2 system? Theriogenology. (2020) 157:210-7. doi: 10.1016/j.theriogenology.2020.06.031

59. Hasan MM, Viil J, Lättekivi F, Ord J, Reshi QUA, Jääger K, et al. Bovine follicular fluid and extracellular vesicles derived from follicular fluid alter the bovine oviductal epithelial cells transcriptome. Int J Mol Sci. (2020) 21:5365. doi: 10.3390/ijms21155365

60. Matsuno Y, Kanke T, Maruyama N, Fujii W, Naito K, Sugiura K. Characterization of mRNA profiles of the exosome-like vesicles in porcine follicular fluid. PLoS ONE. (2019) 14:e0217760. doi: 10.1371/journal.pone. 0217760

61. Ferraz MD, Fujihara M, Nagashima JB, Noonan MJ, Inoue-Murayama M, Songsasen N. Follicular extracellular vesicles enhance meiotic resumption of domestic cat vitrified oocytes. Sci Rep. (2020) 10:8619. doi: 10.1038/s41598-020-65497-w

62. Rodrigues TA, Tuna KM, Alli AA, Tribulo P, Hansen PJ, Koh J, et al. Follicular fluid exosomes act on the bovine oocyte to improve oocyte competence to support development and survival to heat shock. Reprod Fertil Dev. (2019) 31:888-97. doi: 10.1071/RD18450

63. Martinez RM, Liang L, Racowsky C, Dioni L, Mansur A, Adir M, et al. Extracellular microRNAs profile in human follicular fluid and IVF outcomes. Sci Rep. (2018) 8:17036. doi: 10.1038/s41598-018-35379-3

64. Almiñana C, Tsikis G, Labas V, Uzbekov R, da Silveira JC, Bauersachs $\mathrm{S}$, et al. Deciphering the oviductal extracellular vesicles content across the estrous cycle: implications for the gametes-oviduct interactions and the environment of the potential embryo. BMC Genomics. (2018) 19:622. doi: 10.1186/s12864-018-4982-5

65. Banliat C, Le Bourhis D, Bernardi O, Tomas D, Labas V, Salvetti P, et al. Oviduct fluid extracellular vesicles change the phospholipid composition of bovine embryos developed in vitro. Int J Mol Sci. (2020) 21:5326. doi: $10.3390 /$ ijms 21155326

66. Laezer I, Palma-Vera SE, Liu F, Frank M, Trakooljul N, Vernunft A, et al. Dynamic profile of EVs in porcine oviductal fluid during the periovulatory period. Reproduction. (2020) 159:371-82. doi: 10.1530/REP-19-0219

67. Alcântara-Neto AS, Schmaltz L, Caldas E, Blache MC, Mermillod P, Almiñana C. Porcine oviductal extracellular vesicles interact with gametes and regulate sperm motility and survival. Theriogenology. (2020) 155:240-55. doi: 10.1016/j.theriogenology.2020.05.043

68. Alcântara-Neto AS, Fernandez-Rufete M, Corbin E, Tsikis G, Uzbekov R, Garanina AS, et al. Oviduct fluid extracellular vesicles regulate polyspermy during porcine in vitro fertilisation. Reprod Fertil Dev. (2020) 32:409-18. doi: 10.1071/RD19058

69. Qu P, Zhao Y, Wang R, Zhang Y, Li L, Fan J, et al. Extracellular vesicles derived from donor oviduct fluid improved birth rates after embryo transfer in mice. Reprod Fertil Dev. (2019) 31:324-32. doi: 10.1071/RD 18203

70. Gebremedhn S, Gad A, Aglan HS, Laurincik J, Prochazka R, SalilewWondim D, et al. Extracellular vesicles shuttle protective messages against heat stress in bovine granulosa cells. Sci Rep. (2020) 10:15824. doi: 10.1038/s41598-020-72706-Z

71. Li J, Gao H, Tian Z, Wu Y, Wang Y, Fang Y, et al. Effects of chronic heat stress on granulosa cell apoptosis and follicular atresia in mouse ovary. J Anim Sci Biotechnol. (2016) 7:57. doi: 10.1186/s40104-016-0116-6

72. Vanholder T, Leroy JLMR, van Soom A, Opsomer G, Maes D, Coryn $\mathrm{M}$, et al. Effect of non-esterified fatty acids on bovine granulosa cell steroidogenesis and proliferation in vitro. Anim Reprod Sci. (2005) 87:33-44. doi: 10.1016/j.anireprosci.2004.09.006

73. Burton GJ, Jauniaux E. Oxidative stress. Best Pract Res Clin Obstetr Gynaecol. (2011) 25:287-99. doi: 10.1016/j.bpobgyn.2010.10.016

74. Zhang JQ, Gao BW, Wang J, Ren QL, Chen JF, Ma Q, et al. Critical role of FoxO1 in granulosa cell apoptosis caused by oxidative stress and protective effects of grape seed procyanidin B2. Oxid Med Cell Longev. (2016) 2016:6147345. doi: 10.1155/2016/6147345

75. Fujii J, Iuchi Y, Okada F. Fundamental roles of reactive oxygen species and protective mechanisms in the female reproductive system. Reprod Biol Endocrinol. (2005) 3:43. doi: 10.1186/1477-7827-3-43

76. Kehrer JP. The Haber-Weiss reaction and mechanisms of toxicity. Toxicology. (2000) 149:43-50. doi: 10.1016/S0300-483X(00)00231-6
77. Prasad S, Tiwari M, Pandey AN, Shrivastav TG, Chaube SK. Impact of stress on oocyte quality and reproductive outcome. J Biomed Sci. (2016) 23:36. doi: 10.1186/s12929-016-0253-4

78. Al-Gubory KH, Fowler PA, Garrel C. The roles of cellular reactive oxygen species, oxidative stress and antioxidants in pregnancy outcomes. Int $J$ Biochem Cell Biol. (2010) 42:1634-50. doi: 10.1016/j.biocel.2010.06.001

79. Agarwal A, Aponte-Mellado A, Premkumar BJ, Shaman A, Gupta S. The effects of oxidative stress on female reproduction: a review. Reprod Biol Endocrinol. (2012) 10:49. doi: 10.1186/1477-7827-10-49

80. Shkolnik K, Tadmor A, Ben-Dor S, Nevo N, Galiani D, Dekel N. Reactive oxygen species are indispensable in ovulation. Proc Natl Acad Sci USA. (2011) 108:1462-7. doi: 10.1073/pnas. 1017213108

81. Aprioku JS. Pharmacology of free radicals and the impact of reactive oxygen species on the testis. J Reprod Infertil. (2013) 14:158-72.

82. Yang H, Xie Y, Yang D, Ren D. Oxidative stress-induced apoptosis in granulosa cells involves JNK, p53 and Puma. Oncotarget. (2017) 8:25310-22. doi: 10.18632/oncotarget.15813

83. Guerin P, El Mouatassim S, Menezo Y. Oxidative stress and protection against reactive oxygen species in the pre-implantation embryo and its surroundings. Hum Reprod. (2001) 7:175-89. doi: 10.1093/humupd/7.2.175

84. Combelles CMH, Gupta S, Agarwal A. Could oxidative stress influence the in-vitro maturation of oocytes? Reprod Biomed Online. (2009) 18:864-80. doi: 10.1016/S1472-6483(10)60038-7

85. Roth Z, Wolfenson D. Comparing the effects of heat stress and mastitis on ovarian function in lactating cows: basic and applied aspects. Domest Anim Endocrinol. (2016) 56:S218-227. doi: 10.1016/j.domaniend.2016.02.013

86. Roth Z. Effect of heat stress on reproduction in dairy cows: insights into the cellular and molecular responses of the oocyte. Annu Rev Anim Biosci. (2017) 5:151-70. doi: 10.1146/annurev-animal-022516-022849

87. Tatone C, Amicarelli F, Carbone MC, Monteleone P, Caserta D, Marci R, et al. Cellular and molecular aspects of ovarian follicle ageing. Hum Reprod Update. (2008) 14:131-42. doi: 10.1093/humupd/dmm048

88. Alemu TW, Pandey HO, Salilew Wondim D, Gebremedhn S, Neuhof $\mathrm{C}$, Tholen E, et al. Oxidative and endoplasmic reticulum stress defense mechanisms of bovine granulosa cells exposed to heat stress. Theriogenology. (2018) 110:130-41. doi: 10.1016/j.theriogenology.2017.12.042

89. Calderwood SK, Stevenson MA, Murshid A. Heat shock proteins, autoimmunity, and cancer treatment. Autoimmune Dis. (2012) 2012:486069. doi: 10.1155/2012/486069

90. Hou CH, Lin FL, Hou SM, Liu JF. Hyperthermia induces apoptosis through endoplasmic reticulum and reactive oxygen species in human osteosarcoma cells. Int J Mol Sci. (2014) 15:17380-95. doi: 10.3390/ijms151017380

91. Clayton A, Turkes A, Navabi H, Mason MD, Tabi Z. Induction of heat shock proteins in B-cell exosomes. J Cell Sci. (2005) 118:3631-8. doi: $10.1242 /$ jcs. 02494

92. Lancaster GI, Febbraio MA. Exosome-dependent trafficking of HSP70: A novel secretory pathway for cellular stress proteins. J Biol Chem. (2005) 280:23349-55. doi: 10.1074/jbc.M502017200

93. de Maio A. Extracellular heat shock proteins, cellular export vesicles, and the stress observation system: a form of communication during injury, infection, and cell damage. It is never known how far a controversial finding will go! Dedicated to Ferruccio Ritossa. Cell Stress Chaperones. (2011) 16:235-49. doi: 10.1007/s12192-010-0236-4

94. Bewicke-Copley F, Mulcahy LA, Jacobs LA, Samuel P, Akbar N, Pink RC, et al. Extracellular vesicles released following heat stress induce bystander effect in unstressed populations. J Extracellular Vesicles. (2017) 6:1340746. doi: 10.1080/20013078.2017.1340746

95. Zheng Y, Chen $\mathrm{Kl}$, Zheng Xm, Li Hx, Wang Gl. Identification and bioinformatics analysis of microRNAs associated with stress and immune response in serum of heat-stressed and normal Holstein cows. Cell Stress Chaperones. (2014) 19:973-81. doi: 10.1007/s12192-014-0521-8

96. Beam SW, Butler WR. Effects of energy balance on follicular development and first ovulation in postpartum dairy cows. J Reprod Fertil Suppl. (1999) 54:411-24.

97. Sartori R, Sartor-Bergfelt R, Mertens SA, Guenther JN, Parrish JJ, Wiltbank MC. Fertilization and early embryonic development in heifers and lactating cows in summer and lactating and dry cows in winter. J Dairy Sci. (2002) 85:2803-12. doi: 10.3168/jds.S0022-0302(02)74367-1 
98. Walters AH, Pryor AW, Bailey TL, Pearson RE, Gwazdauskas FC. Milk yield, energy balance, hormone, follicular and oocyte measures in early and mid-lactation Holstein cows. Theriogenology. (2002) 57:949-61. doi: 10.1016/S0093-691X(01)00688-4

99. Golini VE, Stradaioli G, Sirard MA. Transcriptome analysis of bovine granulosa cells of preovulatory follicles harvested 30, 60, 90, and 120 days postpartum. Theriogenology. (2014) 82:580-91.e5. doi: 10.1016/j.theriogenology.2014.05.019

100. Contreras GA, Sordillo LM. Lipid mobilization and inflammatory responses during the transition period of dairy cows. Comp Immunol Microbiol Infect Dis. (2011) 34:281-9. doi: 10.1016/j.cimid.2011.01.004

101. Leroy JLMR, Vanholder T, Delanghe JR, Opsomer G, van Soom A, Bols PEJ, et al. Metabolic changes in follicular fluid of the dominant follicle in highyielding dairy cows early post partum. Theriogenology. (2004) 62:1131-43. doi: 10.1016/j.theriogenology.2003.12.017

102. Rukkwamsuk T, Geelen MJ, Kruip TA, Wensing T. Interrelation of fatty acid composition in adipose tissue, serum, and liver of dairy cows during the development of fatty liver postpartum. J Dairy Sci. (2000) 83:52-9. doi: 10.3168/jds.S0022-0302(00)74854-5

103. Poirier M, Tesfaye D, Hailay T, Salilew-Wondim D, Gebremedhn S, Rings F, et al. Metabolism-associated genome-wide epigenetic changes in bovine oocytes during early lactation. Sci Rep. (2020) 10:2345. doi: 10.1038/s41598-020-59410-8
104. Simon C, Greening DW, Bolumar D, Balaguer N, Salamonsen LA Vilella F. Extracellular vesicles in human reproduction in health and disease. Endocr Rev. (2018) 39:292-332. doi: 10.1210/er.201700229

105. Kosaka N, Yoshioka Y, Hagiwara K, Tominaga N, Katsuda T, Ochiya T. Trash or Treasure: extracellular microRNAs and cell-to-cell communication. Front Genet. (2013) 4:173. doi: 10.3389/fgene.2013. 00173

106. Chairoungdua A, Smith DL, Pochard P, Hull M, Caplan MJ. Exosome release of $\beta$-catenin: a novel mechanism that antagonizes Wnt signaling. J Cell Biol. (2010) 190:1079-91. doi: 10.1083/jcb.201002049

Conflict of Interest: The authors declare that the research was conducted in the absence of any commercial or financial relationships that could be construed as a potential conflict of interest.

Copyright (C) 2020 Gebremedhn, Ali, Gad, Prochazka and Tesfaye. This is an openaccess article distributed under the terms of the Creative Commons Attribution License (CC BY). The use, distribution or reproduction in other forums is permitted, provided the original author(s) and the copyright owner(s) are credited and that the original publication in this journal is cited, in accordance with accepted academic practice. No use, distribution or reproduction is permitted which does not comply with these terms. 